\title{
One-Minute Quizzes to Identify Potential Students at RISK IN ENGINEERING COURSES
}

\author{
Andrew Sowinski ${ }^{1}$, Marcel Turcotte ${ }^{2}$, Gilbert Arbez ${ }^{2}$, and David Taylor ${ }^{3}$ \\ ${ }^{1}$ Faculty of Engineering, University of Ottawa, ${ }^{2}$ School of Electrical Engineering and Computer Science, University of \\ Ottawa, ${ }^{3}$ Chemical and Biological Engineering Department, University of Ottawa \\ sowinski@uottawa.ca, garbez@uottawa.ca, turcotte@eecs.uottawa.ca, david.taylor@uottawa.ca
}

\begin{abstract}
Recent years have witnessed increased interest in reducing student attrition at universities due both to matters of improved student outcomes and the practical fiscal benefits accrued from improved retention. The reason for student attrition can be due to many contributing factors (maturity, motivation, external stresses, etc.) and may be difficult to predict. Usually the home Faculty (and sometimes even the student) is only aware of risked academic failure at the end of the semester. At this point it is generally too late for an intervention to be effective.

Although there are numerous intervention models that can be used to help students, these interventions are only effective if students can be identified early in their studies. One method to address this is to assess all students as frequently as possible and in as many courses as possible to create a map of student academic engagement and performance. This paper focuses on the first phase of a long-term study to create such an early warning system to help find students at risk. The first phase consisted of using one-minute quizzes during classes and general attendance to determine the level of engagement of each student. This data was then used to try to identify students in advance that risk academic failure.

It was found that students who regularly missed 30\% of class within the first 5 to 8 classes provided an indication of the likelihood of failure of the student.
\end{abstract}

Keywords: Early warning system, one-minute quizzes, student engagement.

\section{INTRODUCTION}

Retaining students at universities has become one of the top priorities for university administrators, motivated in part by budgetary pressures arising in some instances from tuition fee caps and governmental funding restraints. Meanwhile, a common explanation of the high attrition rates in engineering is that many of the students involved lack the academic skills and abilities meet the demands of their program. While this may be true, attrition involves a complex set of factors that also include the attitude of the students toward engineering, their self-confidence in their skills, and the quality of their interactions with instructors and peers [1]. Ganguly et al. [2] surveyed both first year and senior year students to develop an understanding of their overall impressions of engineering. In the same study, the authors found that first year students missed classes primarily due to what they perceived as unstimulating teaching style $(26.89 \%)$ or in some cases a lack of sleep $(16.80 \%)$. Similarly, the majority $(67.22 \%)$ of the students did not plan their semester workload through a daily, weekly, or monthly planner; they also showed a lack of maturity, a disinterest in the subject matter, and poor time management skills in general. In the same study, senior students were asked to give advice to first year students and the largest response $(45.45 \%)$ was to put academics first, suggesting possible regret on the part of the senior students themselves for not being more serious about their academic studies earlier in their program.

Other studies have shown that students who are more integrated into the college/university environment are more likely to persist in their studies [3] and students who are better adjusted emotionally and socially emerge more likely to complete their college education [4]. These are consistent with students who report that an apparent lack of faculty support in advising, counseling, and tutoring contribute to engineering attrition [5] while positive attitude towards the university, academic self-confidence, and support from professors and friends lead to a better adjustment to higher education [6]. In a multi-institutional study of over 700 engineering students, Vogt [7] also found a strong correlation between the level of faculty interaction and self-efficacy, confidence, and performance. Similarly, students who attended classes had a better academic performance [8].

Finally, many international students face different challenges compared to domestic students, where for example a language barrier language hampers their ability to speak, comprehend, and write in English or French $[9,10]$. Such students also may face higher degrees of anxiety, greater stress, homesickness, and loneliness when compared to domestic counterparts [11]. 
Meeting with students and employing an "intrusive advising" model early in the semester has shown to help improve retention rates [12]. To help students that are at risk of failing, it is therefore important to identify them as quickly as possible and preferably within the first few weeks of the semester. Meanwhile, the popularity of learning analytics has increased significantly, particularly in colleges and universities in the United States [13], where information on students (such as grades, attendance, and engagement through activities on Learning Management Systems, for example) can help to predict students at risk academically on a near day-by-day basis. This has led to the design of Early Warning Systems (EWS) in engineering Faculties to help academic advisors and instructors quickly identify students who may need help [13].

The focus of this paper is to determine whether a suitable correlation exists between student engagement (through attendance tracking and one-minute quizzes) and overall course performance. This study is part of a longterm project to develop an EWS aimed to increase student academic performance and retention. The current study is aimed solely at gathering data to help create a suitable model; appropriate intervention schemes will be considered later in the project.

\section{DATA GATHERING}

This study employed two methods for gathering student engagement data: (i) tracking attendance in lecture and (ii) student participation in lecture-based one-minute quizzes. The data for this paper was collected during the Winter 2017 semester for three $1^{\text {st }}$ year engineering courses.

Attendance was taken manually for a $1^{\text {st }}$ year general course in engineering computation (Course A) taken by all engineering students. Attendance was tracked through signed attendance sheets. The attendance sheets were then transcribed into Excel for the purpose of this research.

One-minute quizzes were used to increase student participation during each class for two sections of a $1^{\text {st }}$ year chemical engineering course (one French section - Course B - and one English section - Course C). The quizzes were conceptually based and were used to gauge student knowledge on a continual basis. Course B completed the one-minute quizzes by hand, and the results were transcribed in Excel. In Course A, the one-minute questions were administered electronically through the online quizzing tool Socrative (www.socrative.com). The data was then aggregated and stored in Excel. For the purpose of this study, only active participation in the oneminute quizzes was tracked (i.e., the scores were not considered).
At the end of the semester, the final grades of the students were also gathered and linked to the participation data.

\section{RESULTS AND DISCUSSION}

The data from the three courses were gathered and analyzed for possible trends. For these courses, a final grade below $50 \%$ denoted a failure. Likewise, students who did not write the final exam were included in the failing cohort. (It was noted that many of the students who deferred writing a final exam had recurring issues that would classify them as students at risk.)

Table 1 summarizes the total number of failures in each course, as well as the percentage of failing students who did not attend $30 \%$ or more of the classes. The threshold of $30 \%$ or more missed classes was arbitrarily chosen as the baseline target in all three courses.

Table 1: The failure rates for three courses depending on class attendance.

\begin{tabular}{|l|c|c|c|}
\hline Description & $\begin{array}{c}\text { Course } \\
\text { A }\end{array}$ & $\begin{array}{c}\text { Course } \\
\text { B }\end{array}$ & $\begin{array}{c}\text { Course } \\
\text { C }\end{array}$ \\
\hline $\begin{array}{l}\text { Number of students in the } \\
\text { course }\end{array}$ & 79 & 22 & 112 \\
\hline $\begin{array}{l}\text { Number of students who } \\
\text { failed the course or } \\
\text { deferred the final exam }\end{array}$ & 9 & 4 & 17 \\
\hline $\begin{array}{l}\text { Number of students who } \\
\text { failed the course or } \\
\text { deferred the final exam } \\
\text { and did not attend } 30 \% \text { or } \\
\text { more of the classes. }\end{array}$ & 3 & 2 & 9 \\
\hline $\begin{array}{l}\text { Percentage of the failing } \\
\text { students who did not } \\
\text { attend } 30 \% \text { or more } \\
\text { classes. }\end{array}$ & $33.3 \%$ & $50.0 \%$ & $52.9 \%$ \\
\hline
\end{tabular}

While it is useful to estimate the percentage of failing students who simultaneously missed $30 \%$ or more classes by the semester's end, the long-term goal of the study is to identify within the first few weeks of the semester those students who are most at risk. Undoubtedly, some of the students who missed $30 \%$ or more classes still succeeded in the course, which would correspond to a false positive result for students at risk. To simulate an EWS, the attendance data was ordered by date and the percent attendance of each student was calculated cumulatively over time. For example, a student who attended the first two classes but missed the third would have an attendance record of $100 \%$ after the first two classes, and $66.7 \%$ after the third. With each class, students were then identified if they exceeded the $30 \%$ threshold. 
a)

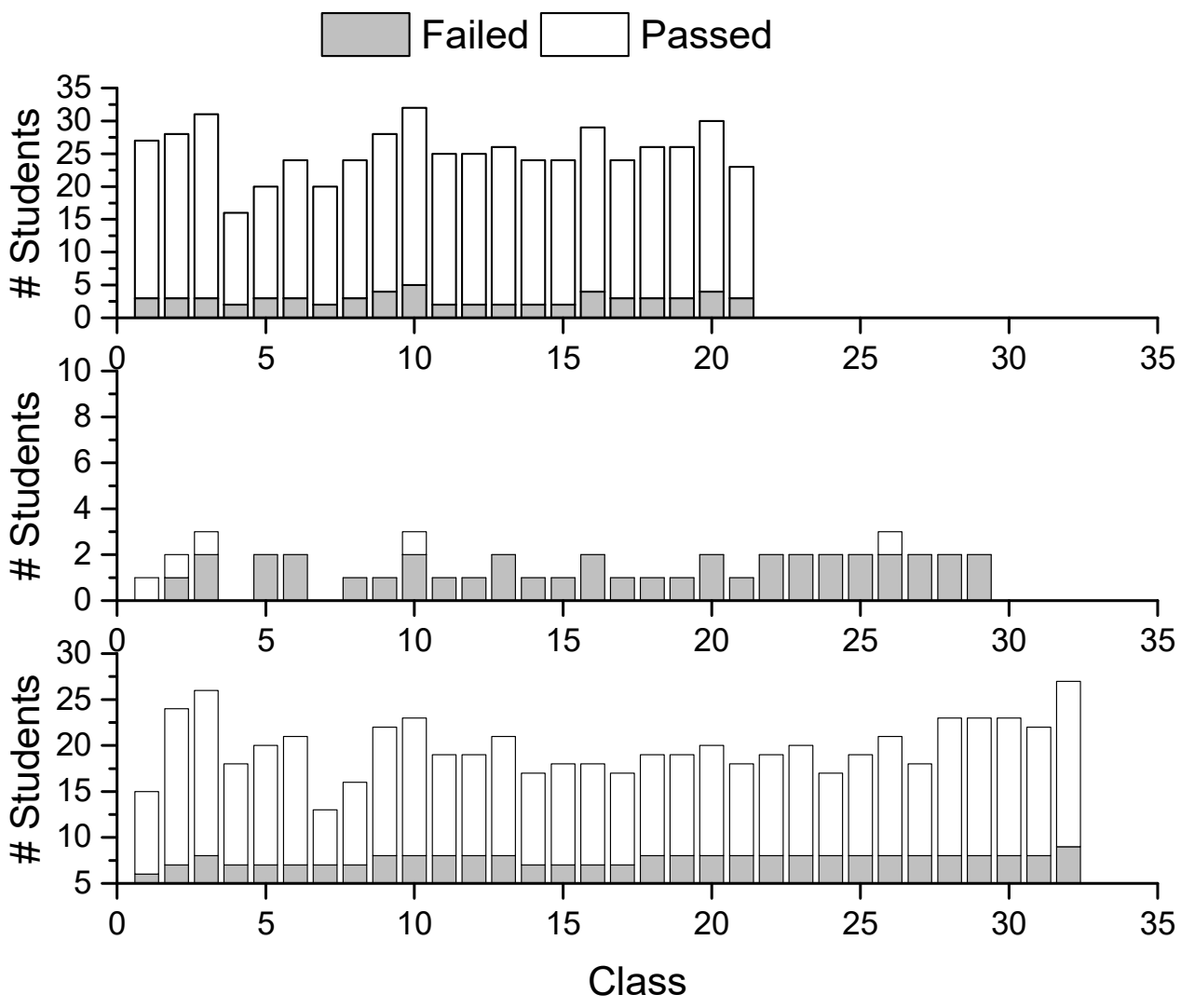

Fig. 1: The number of students who were identified (passed or failed) as missing $30 \%$ or more cumulative classes for a) Course A, b) Course B, and c) Course C.

The students identified fell into the two categories based on their final grade: those students who did eventually fail, and those who passed (i.e. the false positives). Figure 1 shows the results from this analysis for all three courses. The objective was to minimize the number of false positives and to maximize the number of true failures detected at the given threshold $(30 \%)$. (Note that the difference in the number of classes between the three courses is reflective of the number of times the attendance was recorded.)

In Course B the model is relatively effective at predicting those students likely to fail, while minimizing the number of false positives. However, this is possibly related both to the relatively small class size (22 students) and certainly to the arbitrary choice of threshold level (i.e. $30 \%$ here). With the larger classes, there were many false positives predicted, though this number is lowest when considering the first two to three weeks of the semester (i.e. lecture numbers 5 through to 8 ). This threshold (30\%) and timeline ( 5 to 8 classes) could therefore potentially provide an initial marker for starting an intervention for these students. Meanwhile, meeting all students identified at risk- including those who would represent false positives - would potentially help them all academically.

\section{CONCLUSIONS}

The data retrieved in this first study suggests a possible correlation between attendance and the likelihood to fail a course. While the correlation is strongest when considering the semester as a whole, it may be possible to identify at least some of the students at risk as early as the first two to three weeks of the semester. Further, student engagement in lecture-based activities such as short quizzes appear to better predict risk than the simple tracking of attendance through sign-in sheets.

This project was the first phase of a multi-year plan to develop an EWS system at the University of Ottawa. Currently only attendance was used to determine student engagement, but in the future additional sources of data could be used such as participation in online discussion forums and participation in both mandatory and optional assignments. 
Proc. 2017 Canadian Engineering Education Association (CEEA17) Conf.

\section{ACKNOWLEDGEMENTS}

The authors would like to acknowledge the support of the Faculty of Engineering at the University of Ottawa in this project. The authors would also like to thank Professor Jean-Philippe St-Pierre from the Chemical and Biological Engineering department at the University of Ottawa for providing some of his class data.

\section{REFERENCES}

[1] Richard M. Felder, Gary N. Felder, and E. Jacquelin Dietz, "A Longitudinal Study of Engineering Student Performance and Retention. V. Comparisons with Traditionally-Taught Students," Journal of Engineering Education, vol. 87, no. 4, pp. 469-480, 1998.

[2] Sohinee Ganguly, Mrinmoyi Kulkarni, and Meenakshi Gupta, "The Engineering Undergraduate Experience: A Qualitative Perspective,” Psychological Studies, vol. 58, no. 3, pp. 248-258, 2013.

[3] Vinccent Tinto, Leaving college: Rethinking the causes and cures of student attrition. Chicago, IL, Univeristy of Chicago Press. $2^{\text {nd }}$ edition, 312 pp., 1994.

[4] Hilary Gerdes, and Brent Mallinckrodt, "Emotional, social and academic adjustment of college students: a longitudinal study of retention," Journal of Counselling and Development, vol.72, no. 3, pp. 281-288, 2011.

[5] Elaine Seymour, and Nancy M. Hewitt, Talking about leaving: Why undergraduates Leave the Sciences. Boulder, CL. Westview Press. $1^{\text {st }}$ Edition, 444 pp., 2000. \{ISBN: $9780813366425\}$.
[6] William E. Martin Jr., Jody L. Swartz-Kulstad, and Michael Madson, "Psychosocial factors that predict the college adjustment of first-year undergraduate students: Implications for college counsellors," Journal of College Counselling, vol. 2, no. 2, pp. 121-133, 1999.

[7] Christina M. Vogt, "Faculty as a critical juncture in student retention and performance in engineering programs," Journal of Engineering Education, vol.97, no 1, pp. 27-36, 2008.

[8] John CK Cheung, "Class attendance and performance, which comes first?" $20^{\text {th }}$ Autralasian Association for Engineering Conference, (University of Adelaide, Adelaide, South Australia 6-9 December 2009), 2009.

[9] Maureen Snow Andrade, "International students in English-speaking universities: Adjustment Factors," Journal of Research in International Education, vol. 5, no. 2, pp. 131-154, 2006.

[10] Liying Cheng, Johanna Myles, and Andy Curtis, "Targeting language support for non-native English speaking graduate students at a Canadian University," TESL Canadian Journal, vol. 21, no. 2, pp. 50-71, 2004.

[11] Sushama Rajapaksa, and Lauren Dundes, "It's a long way home: International student adjustment living in the United States," College Student Journal, vol. 35, no. 1, pp. 52-62, 2002.

[12] Dana L. Heisserer, and Phil Parette, "Advising at-risk students in college and university settings," College Student Journal, vol. 36, no. 1, pp.69-83, 2002.

[13] Johann Ari Larussonm and Brandon White, Learning Analytics: From Research to Practice, New York NY, Springer, 195 pp., 2014 \{ISBN: 978-1-4614-3304-0\}.
CEEA17; Paper 145

University of Toronto; June 4-7, $2017 \quad-4$ of $4-$ 